\title{
Effect of microwave power on EPR spectra of thermally sterilized eucerinum anhydricum
}

Pawel Ramos, Piotr Pepliński, Barbara Pilawa

\begin{abstract}
Free radicals formed during thermal sterilization of eucerinum anhydricum - the pharmaceutical base were examined by an X-band $(9.3 \mathrm{GHz})$ spectrometer. Eucerinum anhydricum was sterilized at different physical conditions according to the Polish Pharmacopeia norms. The samples were heated at temperatures: $160^{\circ} \mathrm{C}$ $(120 \mathrm{~min}), 170^{\circ} \mathrm{C}(60 \mathrm{~min})$, and $180^{\circ} \mathrm{C}(30 \mathrm{~min})$. The aim of this study is to compare free radical concentration and effect of microwave power on EPR spectra of eucerinum anhydricum base thermally sterilized at different temperatures and periods of time. The effect of time storage on the free radicals in the heated samples was tested. Free radical concentrations in the sample stored 15 min strongly decreased with the increasing of sterilization temperature, probably as the result of recombination. Storage caused strong decrease of free radical concentrations in the samples, probably as the result of interactions with oxygen. It was observed to be independent of sterilization conditions from 2 days of storage and longer. Because of the lowest free radical concentration, for eucerinum anhydricum thermal sterilization at $180^{\circ} \mathrm{C}$ for $30 \mathrm{~min}$ is recommended. The sterilized samples should be stored at inert atmosphere without oxygen molecules. Fast spin-lattice relaxation processes existed in sterilized eucerinum anhydricum. The character of changes of amplitudes and linewidths of EPR lines with increasing of microwave power was the same for different storage times. The parameters of thermal sterilization and storage time influenced free radical concentration in eucerinum anhydricum, but magnetic spin-lattice interactions were unchanged. The usefulness of EPR spectroscopy in optimization of thermal sterilization process of eucerinum anhydricum was confirmed.
\end{abstract}

Key words: EPR • microwave saturation • free radicals $\bullet$ eucerinum anhydricum $\bullet$ thermal sterilization

P. Ramos ${ }^{\bowtie}$, P. Pepliński, B. Pilawa

Department of Biophysics,

School of Pharmacy with the Division of Laboratory

Medicine in Sosnowiec,

Medical University of Silesia in Katowice,

8 Jedności Str., 41-200 Sosnowiec, Poland,

E-mail: pawelramos@sum.edu.pl

Received: 11 September 2014

Accepted: 30 January 2015

\section{Introduction}

Substances interacting pharmacologically and the pharmaceutical bases during drug production are sterilized $[1,2]$. The sterilized products should be free from high levels of free radicals and their structure should be unchanged $[1,2]$. In this work, the original and sterilized eucerinum anhydricum base was tested. The popular method of removing microorganisms from the base is thermal sterilization [1-5]. Different temperatures and relative times of heating are necessary [1-3]. The physical parameters of thermal sterilization are determined by norms $[1$, $2]$. The properties of sterilized substances should be also stable during their storage after sterilization.

The aim of our studies was to compare free radical concentration and the effect of microwave power on electron paramagnetic resonance (EPR) spectra of eucerinum anhydricum thermally sterilized at different temperatures and times. The changes in free radical system of this pharmaceutical base after heating in hot air with increasing time of storage was observed. The conditions of thermal sterilization producing lower amounts of free radicals in eucerinum anhydricum were searched. 
The examination of the effect of microwave power on EPR spectra of the thermally sterilized pharmaceutical base was proposed to test stabilization of its structure. It was expected by us that the similar character of correlations between parameters of the EPR spectra of the original and sterilized eucerinum anhydricum indicates that heating of the samples did not considerably modify its chemical building.

\section{Experimental}

\section{Samples}

Eucerinum anhydricum - the standard pharmaceutical base used in pharmacy was tested in this work. Eucerinum anhydricum is the anhydrous base homogeneous, slightly translucent soft-mass sample $[3,4,6]$. Its consistency is very soft, and eucerinum anhydricum is ointment is used as standalone or in ointment base combination with other components $[3,4,6]$. The total water contents in eucerinum anhydricum is about $220-300 \mathrm{~g}$ of water per $100 \mathrm{~g}$ of base at a temperature of $20^{\circ} \mathrm{C}$, which makes the base a valuable absorbent substrate [3, 4, 6].

Eucerinum anhydricum was sterilized according to the Polish Pharmacopeia IX norms [1]. Sterilization was performed in hot air oven with air circulation produced by Memmert firm (Germany). The following conditions of sterilization processes were used: (a) $T=160^{\circ} \mathrm{C}$ and $t=120 \mathrm{~min}$, (b) $T=170^{\circ} \mathrm{C}$ and $t=60 \mathrm{~min}$, and (c) $T=180^{\circ} \mathrm{C}$ and $t=30 \mathrm{~min}$, where $T$ is temperature and $t$ is time of sterilization, respectively. The sterilized samples were stored at room temperature in air.

The first-derivative EPR spectra were measured at room temperature at $15 \mathrm{~min}$, and on days 2,8 , $10,13,16,22,32$, and 40 after thermal sterilization. The EPR measurements were performed by using an X-band $(9.3 \mathrm{GHz})$ EPR spectrometer with magnetic modulation of $100 \mathrm{kHz}$ produced by Radiopan firm (Poznań, Poland). Numerical acquisition of the spectra was done by the Rapid Scan Unit of Jagmar firm (Kraków, Poland). The spectroscopic programs of Jagmar (Kraków, Poland) and LabView (National Instruments, U.S.A.) were applied during the measurements and analysis of the EPR spectra. The EPR spectra were recorded in the range of microwave power from 2.2 to $70 \mathrm{~mW}$.

Free radical concentrations $(N)$ in the tested samples were determined as the comparison with ultramarine - the reference. The second reference - the ruby crystal was also used. The values of free radical concentrations $(N)$ were calculated from the tests with the low microwave power of $2.2 \mathrm{~mW}$ as $[7,8]$ :

$$
N=N_{u}\left[\left(W_{u} A_{u}\right) / I_{\mathrm{u}}\right] \cdot[I /(W A m)]
$$

where: $N_{u}$ - the number of paramagnetic centers in the reference - ultramarine; $W, W_{u}$ - the receiver gains for the tested samples and the ultramarine; $A, A_{u}$ - the amplitudes of ruby signal for the tested samples and the ultramarine; $I, I_{u}$ - the integral

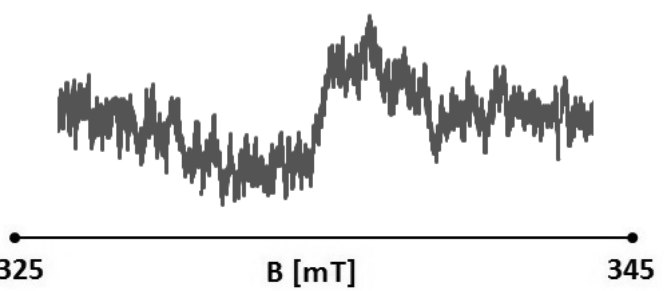

Fig. 1. EPR spectrum of eucerinum anhydricum sterilized at temperature $160^{\circ} \mathrm{C}$ for $120 \mathrm{~min}$. The spectrum was recorded with microwave power of $2.2 \mathrm{~mW}$. B - magnetic induction.

intensities for the tested samples and ultramarine, $m$ - the mass of the sample.

The number of paramagnetic centers in ultramarine was determined chemically. The integral intensities $(I)$ of the EPR lines were obtained from double integration of the first-derivative curves.

g-Factors, amplitudes $(A)$, and linewidths $\left(\Delta B_{\mathrm{pp}}\right)$ of the EPR spectra, were obtained. The influence of microwave power $(2.2-70 \mathrm{~mW})$ on amplitudes $(A)$, and linewidths $\left(\Delta B_{\mathrm{pp}}\right)$, was evaluated.

$g$-Factors were calculated from the formula $[7,8]$ :

$$
g=h v / \mu_{\mathrm{B}} B_{r}
$$

where: $h$ - Planck constant, $v$ - microwave frequency, $\mu_{\mathrm{B}}-$ Bohr magneton, $B_{r}$ - induction of resonance magnetic field. Microwave frequency $(v)$ was measured by MCM101 recorder of EPRAD firm (Poznań, Poland).

\section{Results and discussion}

EPR spectra were not obtained for the original $\mathrm{eu}$ cerinum anhydricum - pharmaceutical base. EPR signals were observed for all the thermally sterilized eucerinum anhydricum samples. The exemplary EPR spectrum of the sample heated at $160^{\circ} \mathrm{C}$ is shown in Fig. 1.

The parameters of the EPR spectra of the heated eucerinum anhydricum depended on microwave power. The changes of amplitudes $(A)$ of the EPR spectra of eucerinum anhydricum sterilized at 160, 170 , and $180^{\circ} \mathrm{C}$ with increasing of microwave power are shown in Figs. 2a-c, respectively. The influence of microwave power on linewidths $\left(\Delta B_{\mathrm{pp}}\right)$ of the EPR spectra of eucerinum anhydricum sterilized according to the norms are shown in Figs. 3a-c, respectively. The data on Figs. 2 and 3 reflect correlations for the eucerinum anhydricum, pharmaceutical base, tested 15 min and 2 days after sterilization.

Amplitudes $(A)$ of the EPR spectra of thermally sterilized eucerinum anhydricum increases with increasing of microwave power in the used range from 2.2 to $70 \mathrm{~mW}$ for the samples heated in all the tested temperatures $\left(160,170\right.$, and $\left.180^{\circ} \mathrm{C}\right)$ (Figs. 2a-c). The effect of microwave saturation of the EPR lines was not observed. The correlations between amplitudes $(A)$ and microwave power $\left(M / M_{o}\right)$ presented in Figs. 2a-c are characteristic for fast spin-lattice relaxation processes in the samples $[7,8]$. Fast spin-lattice relaxation processes existed 
in eucerinum anhydricum 15 min and 2 days after thermal sterilization. The EPR lines of eucerinum anhydricum were not microwave saturated for our observation performed up to 40 days after thermal sterilization. It indicates that spin-lattice magnetic interactions are similar in the base sterilized in different temperatures and they did not changes during storage of the samples.

The increase of linewidths $\left(\Delta B_{\mathrm{pp}}\right)$ of eucerinum anhydricum sterilized at temperature $160^{\circ} \mathrm{C}$ with increasing of microwave power $\left(M / M_{o}\right)$ was observed (Fig. 3a). We obtained the broadening of EPR lines with increase of microwave power for the samples examined $15 \mathrm{~min}$ after thermal sterilization as well as for the longer storage samples. The rise of linewidths of EPR lines for higher microwave power (Fig. 3a) is characteristic of homogeneously broadened lines [7, 8]. The increase of linewidths with microwave power was not clearly visible for eucerinum anhydricum sterilized at temperatures 170 and $180^{\circ} \mathrm{C}$ (Figs. 3b,c).

Free radical concentrations $(N)$ in eucerinum anhydricum - pharmaceutical base - depended on

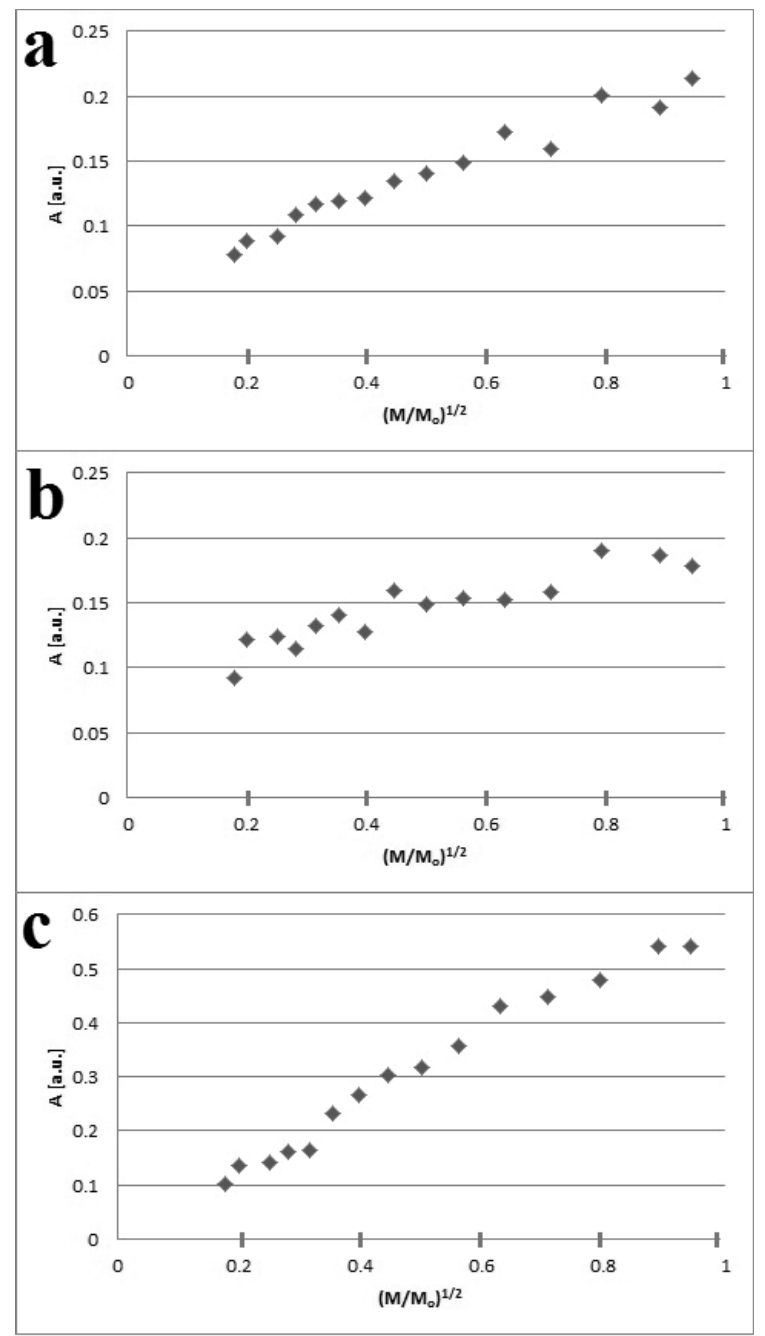

Fig. 2. The influence of microwave power $\left(M / M_{o}\right)$ on amplitude $(A)$ of the EPR line of eucerinum anhydricum sterilized at temperature $160^{\circ} \mathrm{C}$ for $120 \mathrm{~min}(\mathrm{a}), 170^{\circ} \mathrm{C}$ for $60 \mathrm{~min}(\mathrm{~b})$, and $180^{\circ} \mathrm{C}$ for $20 \mathrm{~min}$ (c). $M$ is microwave power used during the measurement of the EPR spectra, $M_{o}$ is the total microwave power produced by klystron $(70 \mathrm{~mW})$. The errors of amplitudes are $( \pm 0.01 \mathrm{a}$. u. $)$. sterilization conditions and on the storage time. Free radical concentrations $(N)$ in the eucerinum anhydricum thermally sterilized at temperatures 160,170 , and $180^{\circ} \mathrm{C}$ at different storage times are presented in Fig. 4.

Thermolysis produced free radicals in the tested base in all physical conditions. A short time after thermal sterilization (15 min), strong decrease of free radical concentration $(N)$ in eucerinum anhydricum with increase of heating temperature was observed (Fig. 4). Probably, the thermally formed free radicals recombine in the heated samples, and this process is more active at higher temperatures. Additionally, free radicals reactions with oxygen during sterilization, performed in circulation of air in the samples environment, may be responsible for the lowering of their levels in the products. Free radical concentrations $(N)$ in the heated eucerinum anhydricum decreased strongly during storage of the samples independent of sterilization conditions from 2 days of storage and longer (Fig. 4). The samples were stored in air, so it was expected that reactions
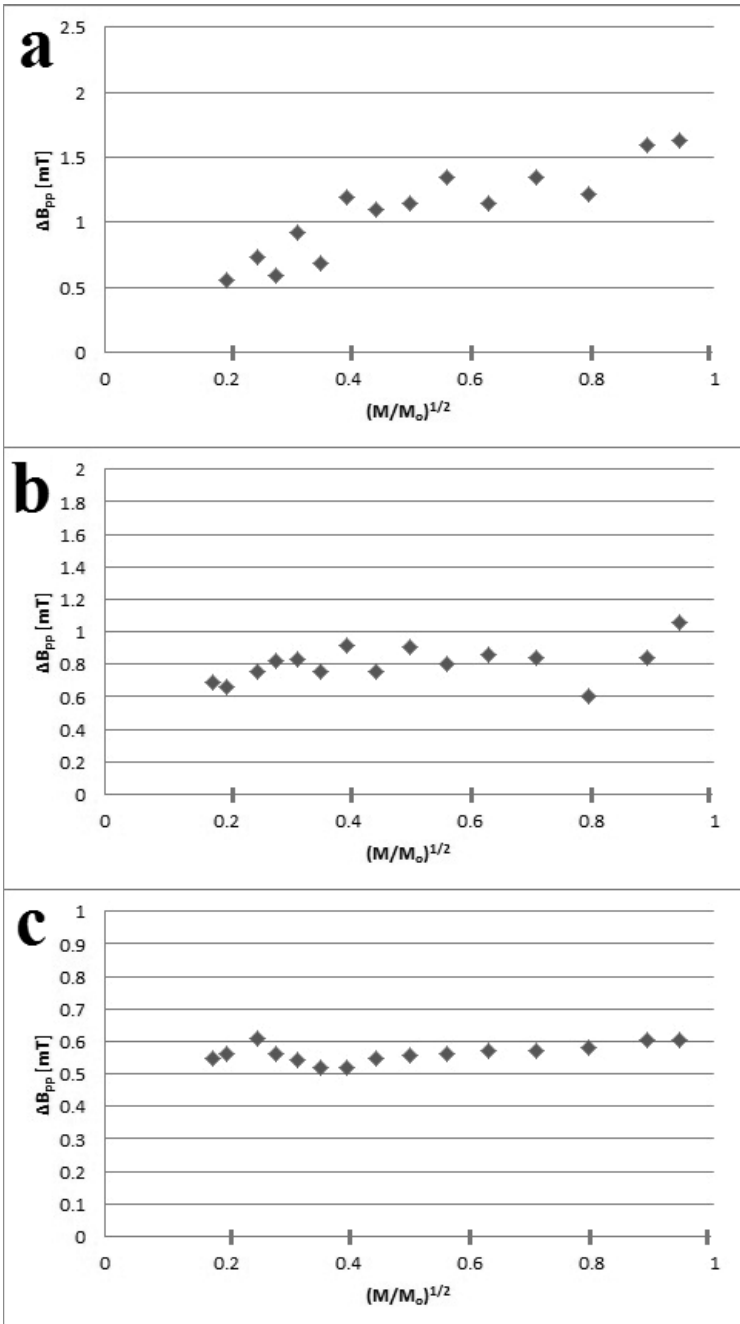

Fig. 3. The influence of microwave power $\left(M / M_{o}\right)$ on linewidth $\left(\Delta B_{\mathrm{pp}}\right)$ of the EPR line of eucerinum anhydricum sterilized at temperature $160^{\circ} \mathrm{C}$ for $120 \mathrm{~min}(\mathrm{a}), 170^{\circ} \mathrm{C}$ for $60 \mathrm{~min}(\mathrm{~b})$, and $180^{\circ} \mathrm{C}$ for $20 \mathrm{~min}$ (c). $M$ is microwave power used during the measurement of the EPR spectra, $M_{o}$ is the total microwave power produced by klystron $(70 \mathrm{~mW})$. The errors of linewidths are $( \pm 0.02 \mathrm{mT})$. 


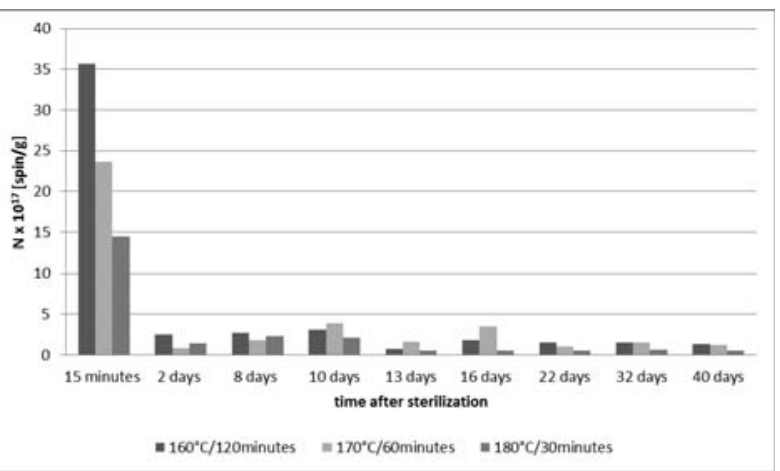

Fig. 4. The effect of storage time on free radical concentrations $(N)$ in eucerinum anhydricum sterilized at temperatures $160^{\circ} \mathrm{C}(120 \mathrm{~min}), 170^{\circ} \mathrm{C}(60 \mathrm{~min})$, and $180^{\circ} \mathrm{C}$ (30 min).

with oxygen molecules may be responsible for such effect. The results contained in Fig. 4 indicated that the parameters of optimal conditions of thermal sterilization of eucerinum anhydricum were temperature of $180^{\circ} \mathrm{C}$ and time of $30 \mathrm{~min}$, because of the lowest free radical concentration. The strong changes of free radical concentrations $(N)$ in the sterilized eucerinum anhydricum during storage in air (Fig. 4) pointed out that the heated samples should be stored at inert atmosphere, which is free of oxygen molecules. The effect of temperature and time of thermal sterilization, and storage time on free radical concentrations in drugs was observed by us earlier [9-15].

EPR examination of heated eucerinum anhydricum performed in this study and our earlier EPR studies of pharmaceutical samples thermally sterilized according to the norms [1] confirmed usefulness of EPR spectroscopy in pharmacy. The basic EPR analysis and microwave effect on spectra may be applied to test optimal conditions of thermal sterilization process.

\section{Conclusions}

EPR studies of thermally sterilized eucerinum anhydricum - pharmaceutical base - pointed out that:

1) Free radicals are formed during sterilization of eucerinum anhydricum at temperatures 160, 170 , and $180^{\circ} \mathrm{C}$ and free radical concentration decreases with increase of heating temperature and storage time. Recombination of free radicals and their interactions with oxygen molecules may be responsible for these effects.

2) Optimal parameters of thermal sterilization of eucerinum anhydricum are temperature of $180^{\circ} \mathrm{C}$ and time of $30 \mathrm{~min}$, because of the lowest free radical concentration.

3) The effect of microwave power on amplitudes of EPR spectra are characteristic of fast spin-lattice relaxation processes in the samples. EPR lines of thermally sterilized eucerinum anhydricum are not saturated in the used range $(2.2-70 \mathrm{~mW})$ of microwave power.

4) The changes of linewidths with increase of microwave power indicate that EPR line of heated eucerinum anhydricum heated at temperature $160^{\circ} \mathrm{C}$ are homogeneously broadened.

5) Examination of eucerinum anhydricum confirm usefulness of EPR measurements with different microwave powers to optimize thermal sterilization process and storage of the pharmaceutical base.

Acknowledgments. This work was financially supported by Medical University of Silesia in Katowice, grants nos. KNW-2-002/N/4/N and KNW-1-005/K/4/0. The authors are grateful to Professor dr hab. Andrzej B. Więckowski for ultramarine used as the reference in our studies.

\section{References}

1. Polish Pharmacopoeia edition IX. (2011). Warsaw: PTFarm (in Polish).

2. PN-EN 556, 2005. Sterilization of medical devices. Requirement for medical devices to be as sterile. Pt. 1: Requirements for terminally sterilized medical devices; PN-EN 556, 2005. Sterilization of medical devices. Requirement for medical devices to be as sterile. Pt. 2: Requirements for medical devices manufactured under aseptic conditons. Warsaw: Polish Committee for Standardization, 2002 (in Polish).

3. Janicki, S., Fiebig, A., \& Sznitowska, M. (2008). Farmacja stosowana. Podrecznik dla studentów farmacji, 4th ed. Warsaw: PZWL.

4. Jachowicz, R. (Ed.). (2008). Receptura apteczna. Podrecznik dla studentów farmacji, 2nd ed. Warsaw: PZWL.

5. Zaręba, M., \& Borowski, J. (2013). Mikrobiologia lekarska. Warsaw: PZWL.

6. Krówczyński, L., \& Jachowicz, R. (2000). Ćwiczenia z receptury. Krakow: Jagiellonian University.

7. Stankowski, J., \& Hilczer, W. (2005). Wstęp do spektroskopii rezonansów magnetycznych. Warsaw: PWN.

8. Wertz, J. E., \& Bolton, J. R. (1986). Electron spin resonance: Elementary theory and practical application. New York: Chapman and Hall.

9. Ramos, P., Pilawa, B., \& Stroka, E. (2013). EPR studies of free radicals in thermally sterilized famotidine. Nukleonika, 58(3), 413-418.

10. Skowrońska, A., Wojciechowski, M., Ramos, P., Pilawa, B., \& Kruk, D. (2012). ESR studies of paramagnetic centers in pharmaceutical materials - cefaclor and clarithromycin as an example. Acta Phys. Pol. A, 121(2), 514-517.

11. Ramos, P., Pilawa, B., \& Adamski, M. (2014). Application of EPR spectroscopy for examination of thermally formed free radicals in drotaverine. Ann. Acad. Medicae Silesiensis, 68(1), 28-37 (in Polish).

12. Ramos, P., Pilawa, B., Krztoń, A., \& Liszka, B. (2012). Free radicals in the thermally sterilized aminoglycoside antibiotics. Pharm. Anal. Acta, 3(9), 1-13.

13. Ramos, P., \& Pilawa, B. (2009). Effect of temperature and time of thermal sterilization on formation of free radicals in isosorbide dinitrate. Farmaceutyczny Przeglad Naukowy, 7(5), 28-33 (in Polish).

14. Ramos, P., Pepliński, P., \& Pilawa, B. (2009). Free radicals in thermally sterilized verapamil. Eng. Biomat., 12(89/91), 162-164.

15. Ramos, P., \& Pilawa, B. (2010). The EPR examination of free radicals formation in thermally sterilized $\beta$-lactam antibiotics. Curr. Top. Biophys., 33, 183-187. 